\title{
¿PUEDE LA MORAL PRESCINDIR DE PRINCIPIOS UNIVERSALES? UNA DISCUSIÓN CON JOSEP CORBÍ
}

Carlos PEREDA

Instituto de Investigaciones Filosóficas Universidad Nacional Autónoma de México jcarlos@servidor.unam.mx

RESUMEN: En su libro Un lugar para la moral, Josep Corbí defiende un realismo moral particularista. En mi discusión enumero algunas dudas que me provoca su proyecto. La duda principal atañe la función que deben tener - si es que se considera que deben tener alguna función - los principios universales en la vida moral.

PALABRAS CLAVE: principios, universalidad, responsabilidad

SUMmaRY: In his Un lugar para la moral (A place for Morality), Josep Corbí argues for a particularist moral realism. In my discussion I express some doubts about the feasibility of his project. My main point concerns the role that universal principles ought to play — if they play any role at all - in moral life.

KEY WORDS: principles, universality, responsibility

Un lugar para la moral (2003) constituye algo así como una Bildungsroman: una novela de aprendizaje conceptual. El autor nos invita a un apasionante viaje - muy bien escrito, por cierto - en el que vamos encontrando muchos de los obstáculos y callejones sin salida con que se topa cualquiera que comienza a reflexionar acerca de la justificación de las evaluaciones morales. Corbí, sin embargo, no empieza su viaje en lo que espontáneamente, en nuestra cultura suele ser el comienzo, sino un poco después del comienzo, pues desatiende los posibles fundamentos religiosos de la moral. Así, Corbí parte de las circunstancias que Max Weber llamó el "desencantamiento del mundo":

Ni las leyes que rigen los astros entienden nada de las inquietudes de María, ni los mecanismos de selección natural le permiten confiar en que sus necesidades como individuo se vean razonable- 
mente atendidas. ¿Qué hacer? [...] Nuestra experiencia interior parece convertirse así en la única fuente de valor. (p. 31)

No obstante, se conoce, la experiencia interior, los gustos y deseos, y la intensidad de los sentimientos con frecuencia varían. Ahora bien, si no podemos respaldar las obligaciones en un terreno tan movedizo, en las momentáneas ganas y desganas, ¿en dónde podríamos respaldarlas?

Por lo pronto, Corbí distingue entre los sentimientos morales y los otros tipos de sentimientos. Con razón, Corbí indica que no es posible descubrir un rasgo interno que haga, de los sentimientos, sentimientos morales. Sin duda, el sentimiento más casual puede ser muy intenso. Su propuesta es: "Los sentimientos no pueden identificarse independientemente de los objetos que los provocan, no pueden variar más que a tenor de alteraciones moralmente relevantes en los objetos que los generan" (p. 55).

A partir de estas observaciones, Corbí introduce un dilema, que podemos llamar el "dilema moderno", al cual intenta dar respuesta en el resto del libro:

O renunciamos a la concepción científica del mundo tradicionalmente aceptada - la visión "desencantada" de la naturaleza - y su manera de concebir lo objetivo y lo subjetivo; o reducimos los juicios morales a los gustos y los apetitos arbitrarios de cada individuo.

Implícitamente, un dilema similar propuso en su momento Fichte, y en años más recientes algo por el estilo presupone John McDowell, en su libro Mind and World, al que tal vez no sin razón se le ha acusado de ofrecer una interpretación fichteana de Kant, un Kant que a veces no distingue claramente entre la razón teórica y la razón práctica. Hago al pasar esta observación histórica porque, si no me equivoco, mi discrepancia básica con el realismo particularista de Corbí tiene que ver con lo que considero su lectura quizá poco productiva de la tradición kantiana, o más bien, de cómo algunos momentos de la tradición kantiana nos pueden ayudar a entender los aspectos universales de la moral y, a la vez, el lugar de la moral en la naturaleza. Pero no nos apresuremos. 
Corbí indica: "Las convicciones morales se parecen ciertamente a los deseos en que nos impulsan a actuar en determinada dirección, pero difieren de ellos en que son fruto de una valoración, de una estimación de la corrección o incorrección de ciertos comportamientos" (p. 68).

Estoy de acuerdo en lo que Corbí afirma de las convicciones morales; sin embargo, tiendo a sospechar que un contraste tal con los deseos permanece demasiado prisionero de un concepto humeano de deseo. Los deseos también nos descubren valores $\mathrm{y}$, a menudo, valores decisivos, valores que, por costumbre o falta de coraje, tendemos a reprimir. Porque los deseos, aunque no son razones, sí son imprescindibles prerrazones. Como las emociones, también la fuerza de los deseos a menudo acaba haciendo trizas más de un sistema de argumentos, en apariencia, rigurosísimo.

En su viaje de reconquista de los fundamentos de la moral, Corbí de pronto introduce el viejo problema de la fortuna moral que conocemos, por lo menos, a partir de la tragedia griega. Corbí observa: "Salvaguardar la responsabilidad moral de los avatares de la fortuna, es disminuir la relevancia de la moralidad en la vida de los seres humanos" (p. 86).

Las relaciones entre responsabilidad y fortuna son complicadas porque el concepto de responsabilidad es vago y, por eso, con límites difusos. De ahí que el concepto de responsabilidad sea resbaladizo: al operar con él fácilmente sucumbimos en un vértigo simplificador o en uno complicador. Frente a la responsabilidad, somos presa de un vértigo simplificador si tenemos un concepto focal de responsabilidad, ese que solemos asociar con el rigorista moral o con el hipócrita, el oportunista y el cínico (¿varias caras de la misma medalla?): yo soy responsable si cumplo puntualmente con mi deber; si con ello todo el proyecto en el que estamos resultará peor, e incluso hasta perecerá el mundo, no es asunto mío. En cambio, sucumbimos en un vértigo complicador si poseemos un concepto totalista de responsabilidad: cuando admitimos imputar responsabilidad sólo si se es responsable de todos los posibles factores que contribuyen a una acción, incluyendo las omisiones. El fatalista 
suele dejarse abrazar por este vértigo complicador, pero también en otros de sus múltiples y lábiles momentos, el hipócrita, el oportunista y el cínico. Si no me equivoco, pues, el concepto de responsabilidad, como todo concepto vago, sólo es claro en sus aplicaciones intermedias. Nadie sería responsable de nada si sólo se admitiese imputar responsabilidad a quien posea control total de una situación (la característica paradoja sorites de todos los conceptos vagos). Pero para ser genuinamente responsables, como Ulises, no podemos dejar de ser prudentes y astutos y, así, no podemos limitarnos a responsabilizarnos sólo de lo que cae directamente - focalmente - bajo nuestro control. En la última afirmación la palabra importante es el adverbio "directamente".

En este sentido tal vez Corbí no tenga razón cuando afirma: "los principios generales no nos ayudan en exceso a la hora de determinar si somos o no responsables de ciertos sucesos" (p. 94).

Al respecto considero que principios morales como el principio de universalidad, el de no tratar a ninguna persona como mero instrumento, el de la autonomía de cada persona, o el de cooperación con las otras personas nos pueden ayudar, por lo menos, de dos maneras.

En primer lugar, indirectamente los principios universales son principios que contribuyen a conformar el carácter: son principios con los cuales no sólo nos autodeterminamos sino que nos autoconstituimos en la persona que somos. Por ejemplo, de caso en caso, nos enseñamos o enseñamos a las generaciones más jóvenes que nunca debemos tratar a los demás como meros medios, incluso cuando esto resulte muy deseable o muy conveniente para nuestros intereses o para los de nuestra causa. Frente a la expresión "de caso en caso, nos enseñamos..." tal vez se pregunte: sí, sí, pero, ¿cómo lo hacemos? Creo que se trata de aprendizajes con la estructura de una espiral crítica: autoconstituyéndonos a partir de ciertos principios, buscamos aquellas virtudes que buscan promoverlos. ¿Con qué virtudes una primera persona trata a una segunda persona nunca meramente como medio? Hemos aprendido en la experiencia que 
buenos candidatos para esas virtudes son la generosidad, la benevolencia, el humor compasivo sobre sí y sobre los otros, cierto tipo de ironía, el coraje... Una vez que hayamos cultivado tales virtudes, probaremos si el ejercicio de tales virtudes conduce a la realización del principio en cuestión y, a su vez, los principios, en cuanto propuestas subdeterminadas, se irán determinando en un ir y venir recíproco y sin fin. Por eso, ninguna de las formulaciones del imperativo categórico kantiano, si se las entiende como sugiero, se opone, o entra en competencia, con uno de los principios universales que Corbí recomienda: siempre es bueno cultivar la percepción de aspectos de un asunto, de una circunstancia. Siempre es bueno ejercitarse para aprender a mirar.

En segundo lugar, directamente, el principio de no tratar a ninguna persona como mero medio nos servirá de guía para autoconstituir la reflexión cuando actuamos. Respecto del principio de no tratar a ninguna persona como mero medio, se enfatizará su carácter de prohibición absoluta indicando que nunca, ni siquiera frente a la causa que consideremos más sagrada, o más útil para nuestra comunidad, y hasta para la humanidad en su conjunto, podremos tener esclavos o ser racistas, podremos poner una bomba en un tren o en una escuela. Por supuesto, parte, pero sólo parte, de la dificultad para entender qué significa no tratar a ninguna persona como mero medio consiste en descubrir a quiénes debemos aplicar el concepto de persona. A partir de los aprendizajes personales, y de los aprendizajes históricos, sabemos que ese concepto ha resultado ser un concepto en expansión. En medio de las luchas sociales y sus diversas argumentaciones se ha ido descubriendo que no sólo los hombres con poder en nuestra tribu son personas, sino también, los que no tienen poder, los obreros y hasta los hombres de la tribu vecina. Con el tiempo, incluso se ha acabado aprendiendo que no sólo los hombres, con poder o sin poder, de mi tribu o de la tribu vecina, con el mismo color de la piel que yo o con otro color, sino que las mujeres son también personas. Sin embargo, no nos engañemos, a diferencia de la estabilidad y la robustez de que disponemos en el conocimiento de la naturaleza, esos aprendizajes son en 
extremo frágiles y con facilidad revocables. La proliferación de campos de exterminio, tan característica del siglo que acaba de terminar, lamentablemente respalda, creo, esta melancólica afirmación.

Si se aceptan, entre otros, estos usos de los principios universales, como elementos que intervienen, pues, tanto en la autoconstitución del carácter como de las acciones, y además, se los ubica como parte de espirales críticas - o si se prefieren otras expresiones, de dialécticas, o de círculos virtuosos, o de equilibrios reflexivos...-, entonces, difícilmente podremos plantear una oposición, como a menudo parece sugerir Corbí, entre instancias universales y particulares de la vida moral. Entre otras razones, porque ninguna de esas instancias se puede constituir independiente de las otras.

Hacia el final de este libro magnífico, Corbí se pregunta:

¿cómo han de entenderse tales reproches [Corbí se refiere a los reproches morales] sino como una mera proyección de los sentimientos de rechazo que los actos de Eichmann y del celador me provocan? ¿En qué sentido podría seguir diciendo que tales actos no sólo los condeno, sino que son condenables? (p. 152)

Sospecho que Corbí considera que esta pregunta, o más bien, que esta acusación de reducir la moral a mera proyección de deseos y emociones, directa o indirectamente, vale tanto para los intentos humeanos o neohumeanos de proponer una teoría proyectiva de la moral, como en contra de los diversos - muy diversos - programas constructivistas que se han propuesto, por lo menos a partir de Kant, e incluso, para ciertas lecturas, de Aristóteles.

Pero estos programas poco o nada tienen que ver entre sí, fuera de oponerse a ciertos tipos de realismo moral - no a todos-, según los cuales los hechos morales están ahí y no tenemos más que abrir los ojos para verlos, y/o los reconstruimos de la misma manera que a los demás hechos. Por este camino se acaba no distinguiendo entre la razón teórica y la razón práctica; pero no hay por qué corregir un error con otro. Podemos tener, 
a la vez, una razón teórica y, así, una naturaleza desencantada y la perspectiva científica que corresponde a ella - en particular, las ciencias naturales - y una razón práctica. Tal vez el dilema moderno que discute Corbí sea un pseudodilema.

Por otra parte, para el proyectivista humeano o neohumeano, los diferentes animales humanos proyectan sus diferentes necesidades, deseos y emociones, idiosincrásicas, particulares y cambiantes, y eso es todo. De ahí que sea fantasioso hablar en sentido estricto de una "necesidad moral". Sin embargo, de seguro no hay necesidades, deseos y emociones humeanas, necesidades, deseos y emociones que no sean prerrazones y, así, que se constituyan por completo independientemente del proceso de dar y pedir razones. En alguna medida, todas y todos reafirmamos o negamos reflexivamente nuestras necesidades, deseos y emociones incluso aquellos en apariencia "más naturales". Ese proceso de reafirmación o de negación, ese proceso de argumentación con los otros y consigo mismo, reitero, se conforma tanto por instancias universales como por particulares y se lleva a cabo, de manera implícita y, en algunas ocasiones, explícitamente, a lo largo de cada vida.

Sin duda, apenas he comenzado la discusión con Corbí. Ojalá que mis muy vacilantes y a menudo enredadas razones, más que para acentuar las diferencias entre dos perspectivas de acercarse a la moral, hayan servido para invitar a leer este libro: para mostrar la riqueza y los sutiles matices con que argumenta Corbí; todo lo que podemos aprender de él. No resisto, sin embargo, narrar todavía una pequeña historia, a la que acabo de asistir en la televisión, y que, me parece, apunta a esa espiral crítica entre lo particular y lo universal: a esa integración recíproca a lo largo de la autoconstitución de un carácter, y de una vida, entre ambas instancias.

Recientemente, cubriendo los criminales atentados ocurridos en Madrid, un reportero entrevistó, en el lugar mismo de la catástrofe, a una vieja señora. No sin impertinencia le preguntó si no veía qué sucedía a su alrededor, si no tenía deseos de escapar, si no le aterraban aquellos cadáveres, porque ella seguía ayudando a los enfermos como si no pasara nada extraordinario, 
como si tranquilamente estuviesen en un día de campo. Frente al silencio de la vieja señora, en un momento, el reportero, un poco exasperado, insistió: "¿por qué lo hace?" Mientras se dirigía a limpiar la herida de una joven desconocida, la respuesta fue rotunda: "Por humanidad."

\section{BIBLIOGRAFÍA}

Corbí, Josep E., 2003, Un lugar para la moral, La balsa de la Medusa, Madrid.

McDowell, John, 1994, Mind and World, Harvard University Press, Cambridge, Mass.

Recibido el 28 de mayo de 2004; aceptado el 7 de julio de 2004. 